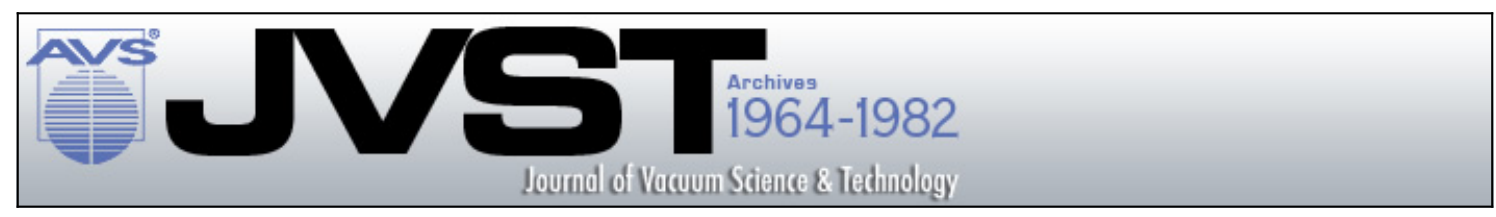

The physical interaction of nitrogen with Pyrex, stainless steel, and nickel at very

\title{
low pressure
}

R. A. Outlaw, F. J. Brock, and J. P. Wightman

Citation: Journal of Vacuum Science \& Technology 11, 446 (1974); doi: 10.1116/1.1318652

View online: http://dx.doi.org/10.1116/1.1318652

View Table of Contents: http://scitation.aip.org/content/avs/journal/jvst/11/1?ver=pdfcov

Published by the AVS: Science \& Technology of Materials, Interfaces, and Processing

\section{Articles you may be interested in}

Adsorption of Mixed Gases on a Pyrex Glass Surface at Very Low Pressures

J. Vac. Sci. Technol. 9, 248 (1972); 10.1116/1.1316572

Physisorption of Nitrogen on 304 Stainless Steel at Very Low Pressures

J. Vac. Sci. Technol. 7, 429 (1970); 10.1116/1.1492888

Adsorption of Nitrogen on a Pyrex Glass Surface at Very Low Pressures

J. Vac. Sci. Technol. 6, 238 (1969); 10.1116/1.1492670

Sealing Pyrex Glass to Stainless Steel and to Inconel

Rev. Sci. Instrum. 33, 1122 (1962); 10.1063/1.1717710

Physical Adsorption of Nitrogen on Pyrex at Very Low Pressures

J. Chem. Phys. 34, 1850 (1961); 10.1063/1.1701099

\section{ADVERTISEMENT}

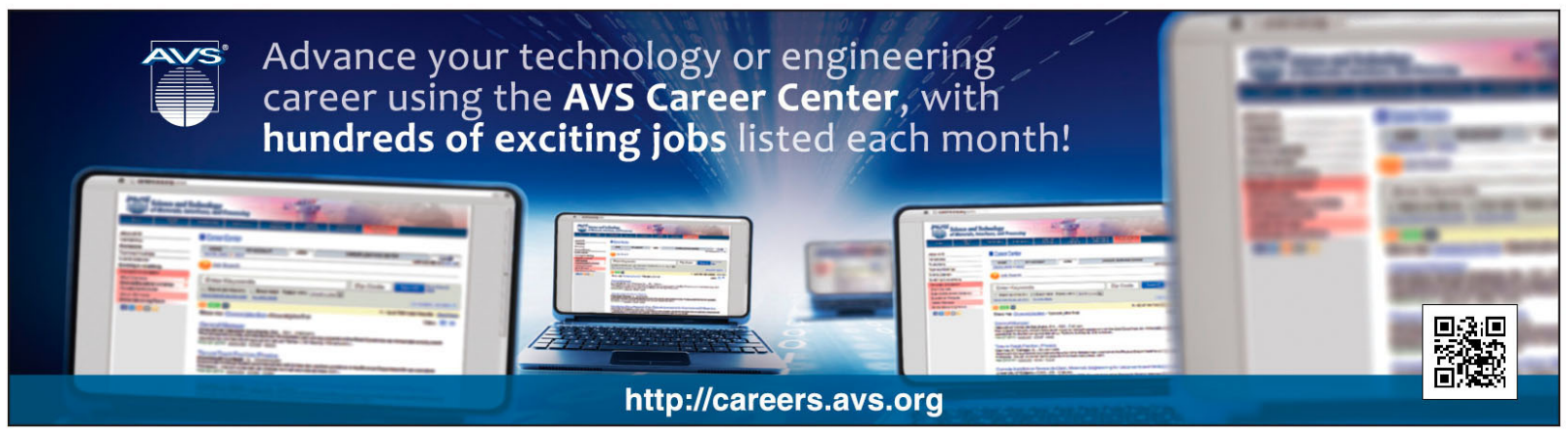




\title{
The physical interaction of nitrogen with Pyrex, stainless steel, and nickel at very low pressure
}

\section{R. A. Outlaw}

NASA, Langley Research Center, Hampton, Virginia 23665

\section{F. J. Brock}

Old Dominion University, Norfolk, Virginia 23508

\section{J. P. Wightman}

Virginia Polytechnic Institute and State University, Blacksburg, Virginia 24061

(Received 30 May 1973; in final form 29 August 1973)

\begin{abstract}
The physical adsorption of nitrogen on the surfaces of Pyrex, 347 stainless steel, and polycrystalline nickel was investigated over the pressure range $1 \times 10^{-12}-3 \times 10^{-7}$ Torr and for the temperatures 77.4 and $87.4^{\circ} \mathrm{K}$. The metal surfaces were prepared hy vacuum firing, by chemical cleaning, and, following bakeout, by electron impact desorption (EID). Work function measurements were used to indicate changes in the surface condition following electron bombardment, and a mass spectrometer was used to monitor gas composition. The isotherms revealed that the stainless surface was very heterogeneous and that the Pyrex surface area hąd a roughness factor of 1.7. Nitrogen isotherms were also taken on the metal surfaces after they had been exposed to oxygen. Very little change in physical adsorption on the nickel was detected, presumably because the chemisorbed oxygen was incorporated into the bulk. The chemical adsorption of $\mathrm{N}_{2}$ on nickel at room temperature and below was not observed.
\end{abstract}

\section{INTRODUCTION}

In many studies of physisorption on multicomponent materials, such as Pyrex and stainless steel, vacuum bakeout has been the principal method used to clean the surface. ${ }^{1-5}$ Since an improvement in surface cleanliness should result in an improvement in experimental data, a substantial effort was made in this work to minimize surface contamination by employing an extensive chemical pretreatment, by using high-temperature bakeout, by using electron impact desorption (EID), and by maintaining a very low ultimate pressure. Pyrex, stainless steel, and nickel were selected as adsorbents because they are common materials used in vacuum instrumentation. Since the interaction of gases with the surfaces of these materials can generate large changes in the environment to be measured, characterization of these interactions is important. The specific question of whether ground-state nitrogen will adsorb on nickel was also investigated. ${ }^{6-10}$

\section{APPARATUS}

The system used in this study is shown schematically in Fig. 1. It is a two-chamber stainless steel system with separate pumping for each chamber. The entire system is evacuated during pumpdown and hakeout by a turbomolecular pump (valves a-g open). During normal operation (valves $\mathrm{d}, \mathrm{f}$, and $\mathrm{g}$ closed) the forechamber is pumped directly by a titanium sublimator and an ion pump having a combined pumping speed of 500 liter/sec for nitrogen. The main chamber is pumped through valve a (conductance $\approx 400$ liter $/ \mathrm{sec}$ ) by a titanium sublimator and an ion pump having a combined pumping speed of 1600 liters/sec for nitrogen. During normal operation valve a, located between the main chamber and its pump, is used as a variable conductance to limit the pumping speed (typically $<50$ liter/sec). Valve $h$ is used to transfer gas from the gas bottle to the gas supply manifold which is maintained at approximately 760 Torr during normal operation. The variable leak, valve $e$, is used to control the input gas flux to the forechamber. Valve $\mathrm{c}$ connects the forechamber to the main chamber through a 0.10 -liter/sec conductance.

The adsorption vessel is attached to the main chamber by a short Pyrex tube which electrically and thermally isolates the adsorption vessel from the main chamber. The temperature of the adsorption vessel is established by immersion in a free-boiling cyrogenic fluid, the level of which is controlled by a movable Dewar. A thoriacoated cathode $\left(1.32 \mathrm{~cm}^{2}\right)$, mounted on support posts

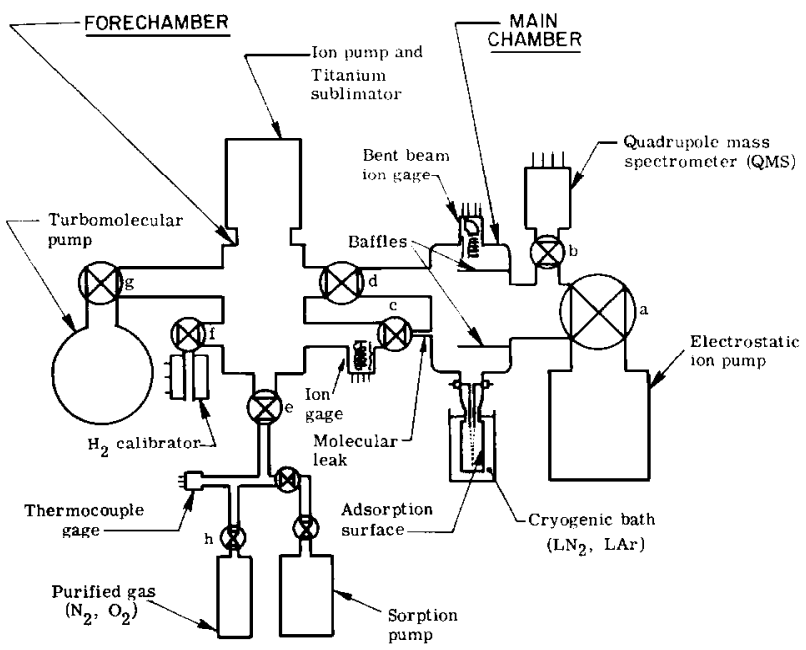

FiG. 1. Schematic of physical adsorption system. 
in the main chamber and extending nearly to the bottom of the adsorption vessel, is used to electron bombard the metal sample surface and to measure the change in its relative work function.

The forechamber pressure is measured with a calibrated Nottingham-type ion gauge, and the main chamber pressure is measured with Helmer-type ion gauge. A calibrated hydrogen source is connected to the system through valve $f$ to periodically check the sensitivity of the system gauges during operation. ${ }^{11}$ A quadrupole mass spectrometer is used to determine the gas composition in the main chamber.

\section{SAMPLE PREPARATION}

The Pyrex (Corning 7740) surface studied in this work was the inner surface of an adsorption vessel, the shape of which is shown in Fig. 2 (dotted lines). The surface area of the opening connecting the vessel to the main system is negligible compared to the surface area of the vessel $(\sim 1 \%)$. The vessel was chemically treated by a four-step process (Diversey) which, from laboratory experience, has been found to effectively clean the surface of many metals and ceramics so that they pass a water-break test (an airbrush-applied water film is completely invisible). The vessel was then ultrasonically scrubbed in distilled water, mounted on the system, evacuated, and baked out at $450^{\circ} \mathrm{C}$ for 4 days. Isotherm measurements were initiated after the system had cooled and ultimate background pressure was attained $\left(\sim 2 \times 10^{-12}\right.$ Torr).

The 347 stainless stcel adsorption vessel was machined from bar stock (commercial grade) to the dimensions shown in Fig. 2 (solid lines). The inside surface was polished with 600 -grit silicon carbide to a surface roughness of $<8 \mu \mathrm{in}$. The vessel was ultrasonically scrubbed in freon and vacuum fired at $1000{ }^{\circ} \mathrm{C}$. The same chemical cleaning process was applied, during which approximately $0.017 \mathrm{~mm}$ of metal was removed from the surface. The vessel was then ultrasonically scrubbed in deionized water, installed on the system, evacuated, and baked out at $450{ }^{\circ} \mathrm{C}$ for 4 days. After cooldown, the inner surface of the vessel was electron bombarded for a total of $40 \mathrm{~h}$ at an incident current density of 0.044 $\mathrm{mA} / \mathrm{cm}^{2}$ to remove surface impuritics by EID. Elcctron bombardment was terminated after $40 \mathrm{~h}$ to maintain the thorium coverage on the sample surface at a value $<0.001$, based on the thorium evaporation rate from the thoria-coated electron bombardment cathode. ${ }^{12}$ Electron bombardment was interrupted periodically to measure the relative work function of the sample surface. Isotherm measurements were initiated after completion of electron bombardment and after the system reached ultimate background pressure $\left(2 \times 10^{-12}\right.$ Torr).

The nickel adsorption vessel was machined to the dimensions shown in Fig. 2 (solid lines) from vacuumcast nickel which had been purified by a three-pass zone refinement (Materials Research Corp.). Typical impurity levels were as follows : carbon, $<.37 \mathrm{ppm}$; oxygen,

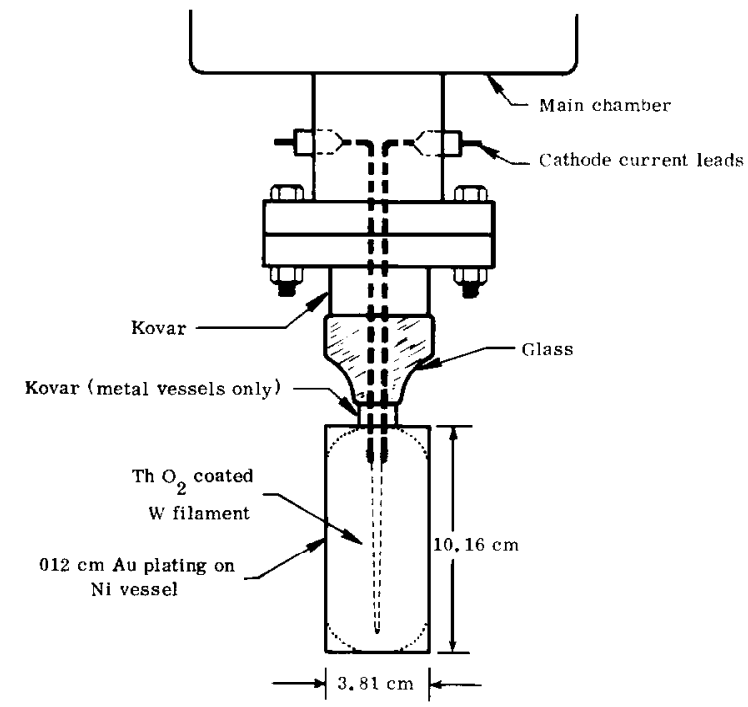

F1G. 2. Schematic of adsorption vessels. 347 stainless steel and nickel geometry, solid line; $\mathrm{A}=135 \mathrm{~cm}^{2}, t_{w}=0.1 \mathrm{~cm}$. Pyrex geometry, dotted line; $A=107.81 \mathrm{~cm}^{2}, t_{w}=0.15 \mathrm{~cm}$.

$<18 \mathrm{ppm}$; phosphorus, $<15 \mathrm{ppm}$; and iron, $<12 \mathrm{ppm}$. The inner surface of the vessel was polished to a surface roughness of $<8 \mu$ in. with 1000 -grit diamond paste. The vessel was ultrasonically scrubbed in freon, vacuum fired at $1000^{\circ} \mathrm{C}$, and chemically cleaned using the above process, during which $0.0017 \mathrm{~mm}$ of nickel was removed. A gold film $0.013-\mathrm{mm}$ thick was electroplated onto the outer surface of the nickel vessel to inhibit the diffusion of atmospheric hydrogen and oxygen into the bulk during extended bakeout at high temperature. The adsorption vessel was ultrasonically scrubbed in deionized water, installed on the system, evacuated, and baked out at $450{ }^{\circ} \mathrm{C}$ for 4 days. After cooldown, the sample surface was electron bombarded until the work function became stable and the mass spectra indicated no significant gas release. Isotherm measurements were initiated after the system reached the ultimate background pressure $\left(\sim 2 \times 10^{-12}\right.$ Torr $)$.

\section{PROCEDURE}

The dynamic technique ${ }^{13}$ was used to determine equilibrium coverage as a function of pressure for a prescribed isotherm temperature. In this technique an equilibrium pressure is established in the main system (including the adsorption vessel) by establishing a steady-state gas flow through the system. The adsorption vessel is abruptly cooled from room temperature to the isotherm temperature, and the change in pressure (in the main system) during adsorption is measured continuously. This pressure change is electronically integrated over the time interval required for the system pressure to again arrive at the initial equilibrium value. A desorption procedure was also used in which the main system pressure was equilibrated with the adsorption vessel at the isotherm temperature and the cryogenic bath was abruptly removed from the adsorption vessel. The change in system pressure from the subsequent desorption was then integrated over the time interval 


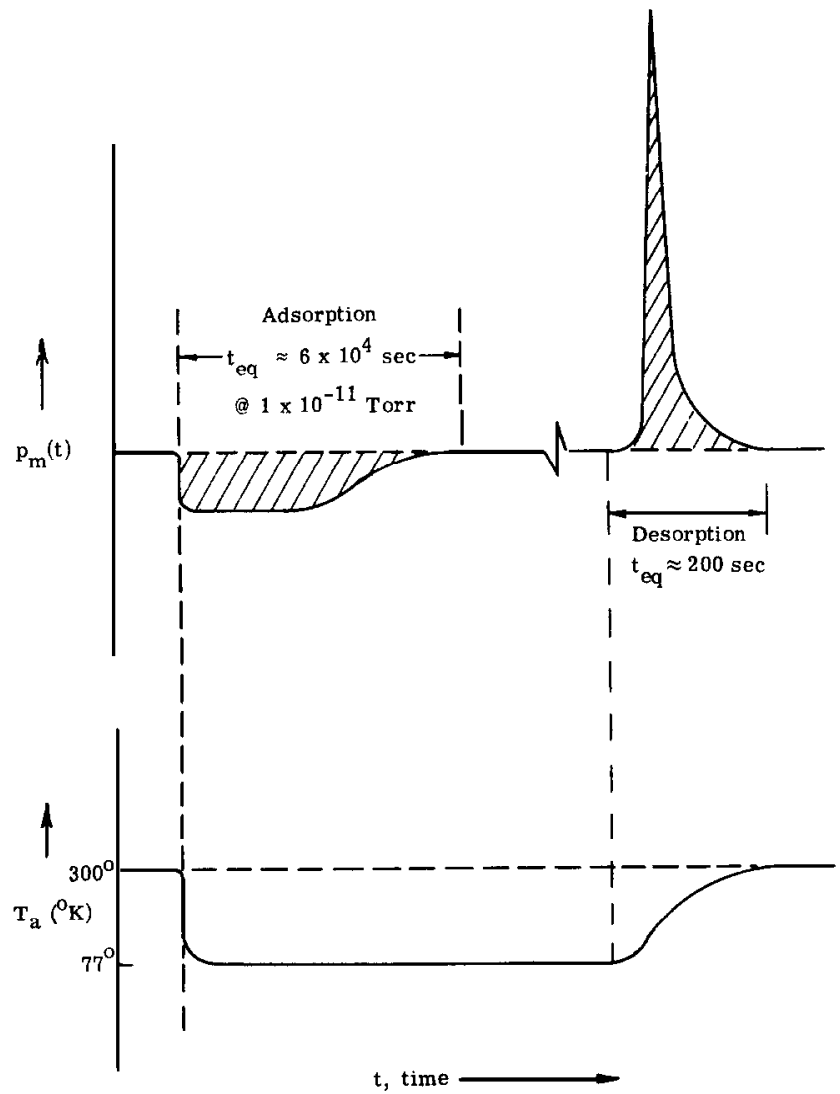

Fig. 3. Pressure and temperature behavior as a function of time characteristic of the dynamic technique.

required for the system pressure to return to its initial value. The surface equilibrium coverage (using either the adsorption or the desorption procedure) is given by

$$
\sigma\left(T_{a}, p_{a}\right)=\frac{1.333 \times 10^{6}}{A k T_{m}} C_{0} \int_{0}^{t_{\mathrm{oq}}} \Delta p_{m} d t,
$$

where $\sigma\left(T_{a}, p_{a}\right)$ is the equilibrium coverage at the equilibrium pressure $p_{a}$ and the isotherm temperature $T_{a}$ $\left(\mathrm{cm}^{-2}\right), C_{0}$ is the limiting conductance between the main system and its pump (liters/sec), $A$ is the adsorption surface area $\left(\mathrm{cm}^{2}\right), k$ is the Boltzman constant $(1.38$ $\left.\times 10^{16} \mathrm{erg} /{ }^{\circ} \mathrm{K}\right), T_{m}$ is the temperature in the main system $\left(298^{\circ} \mathrm{K}\right), \Delta p_{m}=p_{m}(t)-p_{m}(0)$ is the difference between the instantaneous pressure during adsorption or during desorption and the equilibrium pressure in the main system (Torr), $t_{\mathrm{eq}}$ is the time at which the pressure returns to its initial equilibrium value, $p_{a}=\left[\left(T_{m} / T_{a}\right)\right]^{1}$ $\times p_{m}$ (Torr), and $T_{a}$ is the isotherm temperature (adsorption vessel temperature, ${ }^{\circ} \mathrm{K}$ ).

Figure 3 illustrates the integral in Eq. (1), measured during adsorption and during desorption. In preliminary experiments these two areas were separately measured and found to be equal. For example, at an equilbirium pressure of $10^{-9}$ Torr, it was found that the two areas differed by less than $1 \%$.

Since the time required to reach adsorption equilibrium at low pressures is extremely long $\left(6 \times 10^{4} \mathrm{sec}\right.$ at $1 \times 10^{-11}$ Torr), an equilibrium-forcing technique was developed. The adsorption vessel was maintained at isotherm temperature but, rather than maintain the steady-state gas flow into the system (corresponding to a desired equilibrium pressure) for a long time, the input gas flux was increased by several orders of magnitude (determined by forechamber pressure measurments) for an arbitrary time interval. After returning the input gas flux to its original value (determined by the forechamber pressure), the slope of the main chamber pressure, $p_{m}(t)$, was observed for several minutes. If the slope was negative, the above procedure was repeated until a zero slope was observed (equilibrium coverage). If the slope was positive, the input gas flux was decreased by an order of magnitude for a short time interval such that the excess adsorbed gas was desorbed. By using this technique, it was possible to reduce by several orders of magnitude, the time required to reach equilibrium coverage for a prescribed equilibrium pressure for the lower pressure range investigated. Preliminary experiments were conducted in which $\sigma$ was determined (during desorption) for both the equilibrium-forcing technique and the natural technique (at the same equilibrium pressure). It was found that the two techniques yielded values of $\sigma$ which differed by less than $1 \%$. The equilibrium-forcing technique was subsequently used for all $\sigma$ determinations at low equilibrium pressures $\left(<10^{-8}\right.$ Torr $)$.

The nitrogen adsorption data at very low equilibrium pressures was corrected by subtraction of the measured adsorption data for each of the background gases (mostly hydrogen).

Isotherms were constructed from equilibrium coverages calculated from Eq. (1) for a number of equilibrium pressures at two isotherm temperatures, those of freeboiling nitrogen and argon (at 760 Torr).

\section{RESULTS AND DISCUSSION}

\section{$\mathrm{N}_{2} /$ Pyrex}

The 77.4 and the $87.4^{\circ} \mathrm{K}$ isotherms for nitrogen on the chemically cleaned surface of Pyrex are presented in Fig. 4. The data extend over the range $5 \times 10^{10} \leq \sigma$

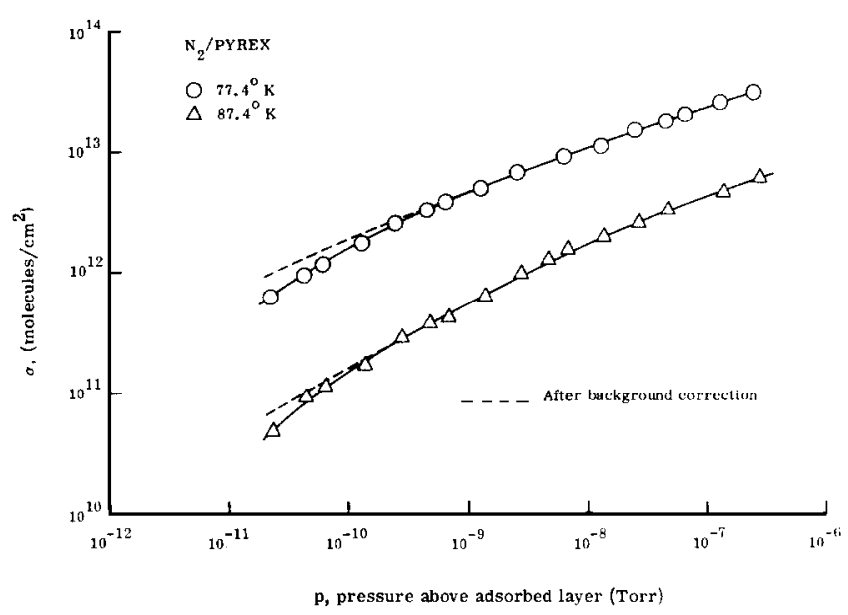

FiG. 4. Physical adsorption isotherms of nitrogen on Pyrex. 


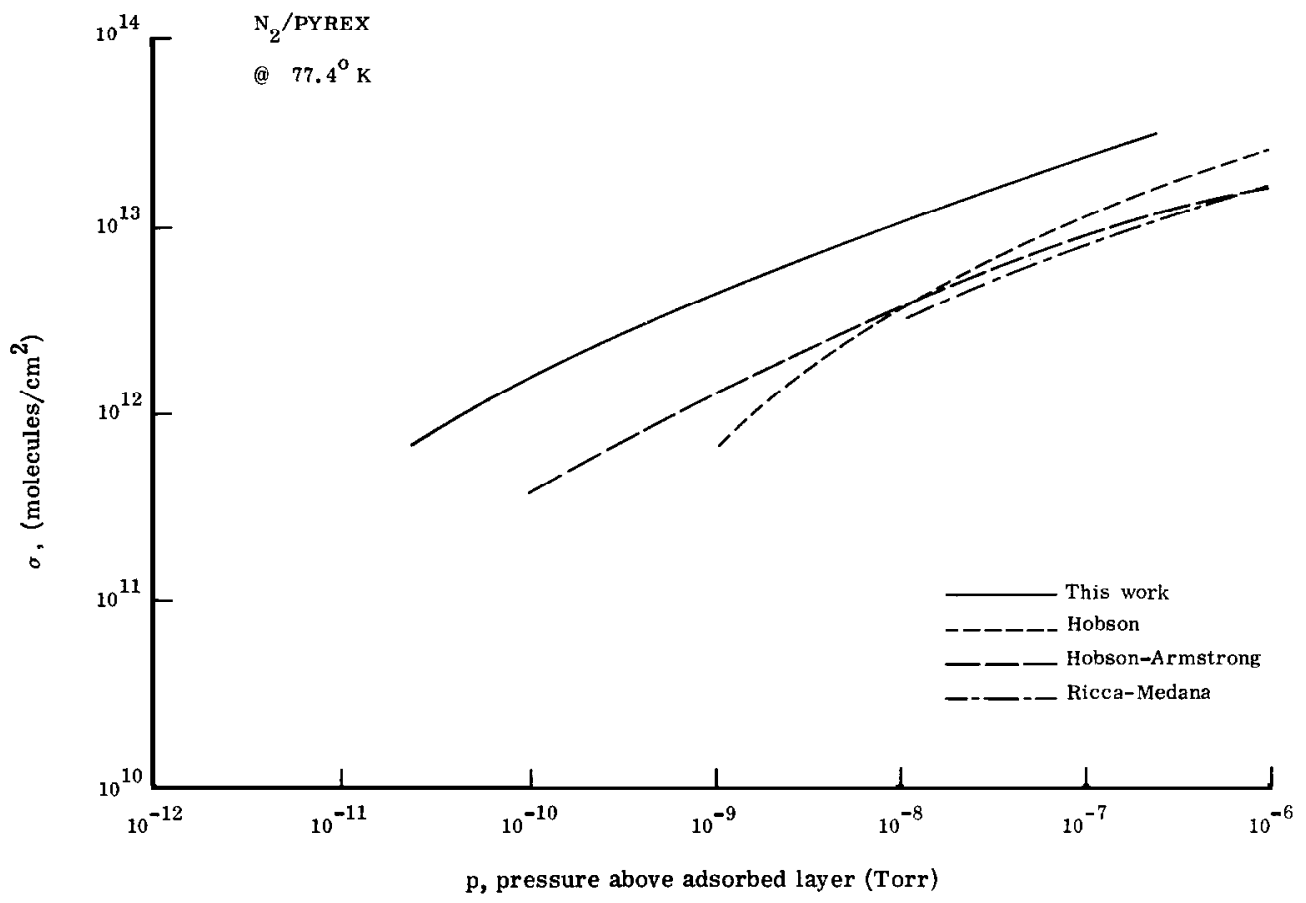

FIG. 5. Comparison of $77^{\circ} \mathrm{K}$ isotherms of nitrogen on Pyrex to that of nitrogen on chemically cleaned Pyrex.

$\leq 3 \times 10^{13}$ molccules $/ \mathrm{cm}^{2}$, corresponding to the pressure range $2 \times 10^{-11} \leq p \leq 3 \times 10^{-7}$ Torr. The shape of the isotherm is in agreement with results reported by others, but the value of $\sigma$ at a given pressure is larger by a factor of about 1.7, as is shown in Fig. 5., ${ }^{2,3}$ All $\sigma$ values are based on the geometric area ; hence, the difference may be attributed to a difference in surface area. The surface area was expected to be greater in this work since the chemical cleaning of the Pyrex would presumably have a leaching effect. The data for Pyrex in the $10^{-11}$-Torr range have a maximum possible error of about $25 \%$ due to the uncertainty in the correction for the background gas adsorption.

Figure 6 shows a fit of the data to the DubininRadushkevich (D-R) equation

$$
\sigma=\sigma_{m} \exp \left(-B \epsilon^{2}\right)
$$

where the Polanyi energy $\epsilon$ is

$$
\epsilon=R T_{a} \ln \left(p_{a} / p_{0}\right)
$$

and $\sigma_{m}$ is the number of molecules adsorbed per unit area forming a complete monolayer, $p_{0}$ is the saturation vapor pressure of the adsorbate at $T_{a}, B$ is a constant, and $R$ is a gas constant. The saturation vapor pressure was obtained from ${ }^{14}$

$$
p_{0}=4.42 \times 10^{6} \exp (-1333 / R T) .
$$

A least-squares analysis of all the data is represented by the straight line in Fig. 6. Separate least-squares analyses were also made for the data at each isotherm temperature. The least-squares analysis for each temperature implied a small variation of the constants $B$ and $\sigma_{m}$ with temperature. The combined data for both temperatures gives $\sigma_{m}=1.08 \times 10^{15}$ molecules $/ \mathrm{cm}^{2}$ and $B^{-1}=1.78 \mathrm{kcal} / \mathrm{mole}$. Comparing the value of $\sigma_{m}$ found in this work with the value obtained by Hobson and
Armstrong $2\left(6.2 \times 10^{14}\right.$ molecules $\left./ \mathrm{cm}^{2}\right)$ indicates a higher surface area by a factor of 1.7 . The higher surface area could result from the leaching effect mentioned above. The mean energy of adsorption is $6.6 \%$ larger than the value obtained by Hobson and Armstrong (1.67 $\mathrm{kcal} /$ mole).

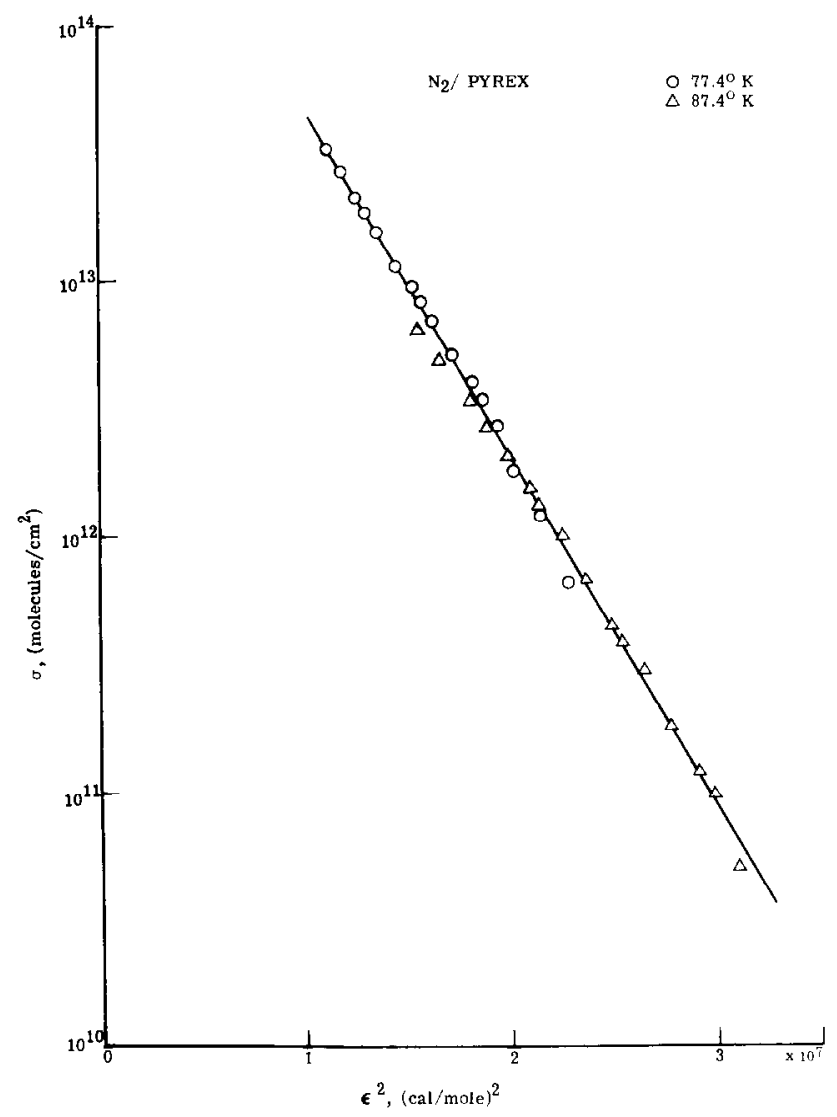

FIG. 6. Dubinin-Radushkevich plot of nitrogen on Pyrex. 


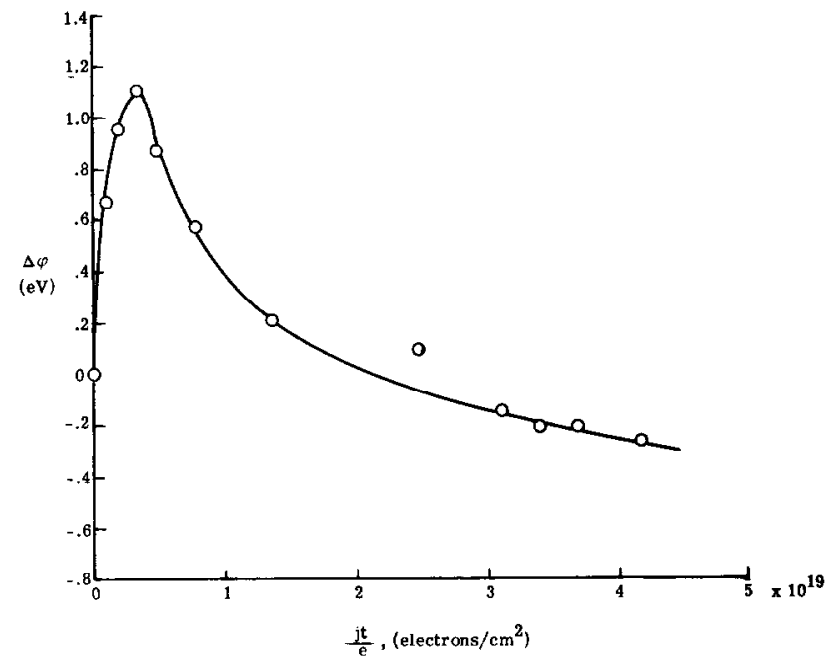

F1G. 7. Work function variation, $\Delta \varphi$, as a function of electron bombardment dose on 347 stainless steel.

The isosteric heat is given by

$$
q_{\mathrm{st}}=-R\left(\frac{\partial \ln p_{a}}{\partial\left(1 / T_{a}\right)}\right)
$$

In this work, the value of $q_{\mathrm{st}}$ was found to be 6.34 $\mathrm{kcal} / \mathrm{mole}$ at a coverage of $5 \times 10^{12}$ molecules $/ \mathrm{cm}^{2}$. Hobson and Armstrong found a value $19 \%$ lower, 5.15 $\mathrm{kcal} / \mathrm{mole}$ at the same coverage. Leaching would tend to remove the alkaline modifying ions from the alkalinerich phase of the glass and leave a slightly porous surface. This porous structure would provide sites where the physical attraction between the adsorbed molecule and the increased number of nearest neighbors is greater. The isosteric heat at the lowest coverage of $9 \times 10^{11}$ molecules $/ \mathrm{cm}^{2}$ was $6.56 \mathrm{kcal} /$ mole.

\section{$\mathbf{N}_{2} / 347$ Stainless Steel}

After bakeout, the stainless steel adsorption vessel was cleaned by EID and the work function was meas- ured frequently to monitor the surface cleanup. The electron energy for EID was $550 \mathrm{eV}$, and the current density was $0.044 \mathrm{~mA} / \mathrm{cm}^{2}$. Figure 7 is a plot of the variation in work function $(\Delta \varphi)$ with bombardment dose $(j t / e)$. An increase in the work function of $1.1 \mathrm{eV}$ occurred in about $3 \mathrm{~h}$ of bombardment and then monotonically decreased from that point on. A possible explanation of such behavior could be the removal of carbon (as $\mathrm{CO}$ and, to a lesser extent as $\mathrm{CO}_{2}$ ) which was distributed throughout the surface metal oxides. The carbon-containing molecules might tend to lower the average work function relative to the work function of the surface oxide, so that as the carbon was removed the work function would tend to increase. Then, as oxygen was desorbed by further bombardment, the work function would decrease. After $40 \mathrm{~h}$ of EID, the work function had somewhat stabilized but a negative slope was still apparent. Bombardment was terminated at this time because complete removal of oxygen from the high-binding-energy surface oxides $\left(\mathrm{Cr}_{2} \mathrm{O}_{3}\right.$ and $\mathrm{Fe}_{2} \mathrm{O}_{3}$ ) would require a substantial increase in the bombardment dosage. The probability of thorium contamination of the sample surface from the electron bombardment cathode would then be unacceptably high.

Figure 8 shows typical mass spectra observed both before and during EID. The total pressure eventually dropped to $<1 \times 10^{-10}$ Torr during bombardment, which indicated relatively little gas desorbing from the surface. The most prominent observed gases were carbon monoxide, hydrogen, and a small amount of carbon dioxide. However, the actual gases desorbed from the surface during EID are not known exactly since the mass spectrometer was not positioned in line of sight with respect to the surface.

Neglecting adsorption from background gases, firstorder electron impact desorption is given by

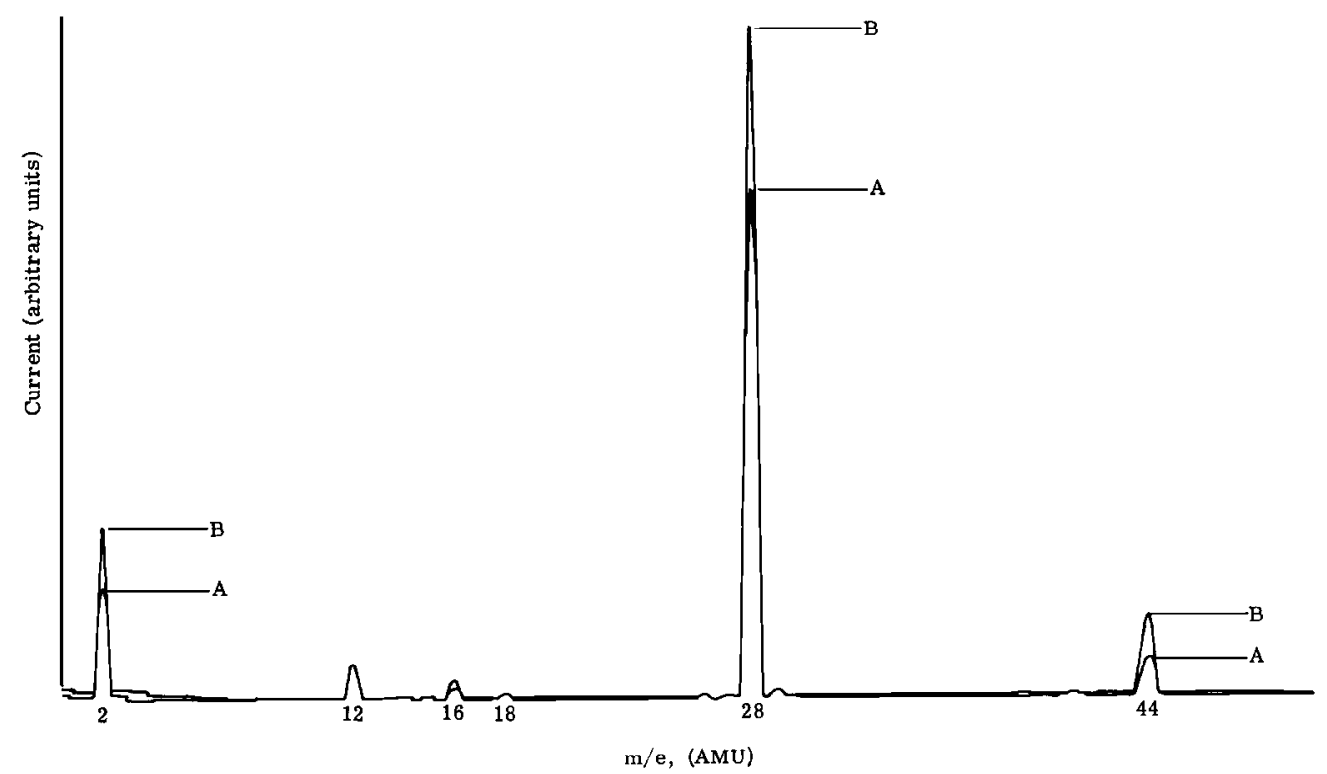

FIG. 8. Mass spectra of the gas composition before and during electron bombardment of 347 stainless steel. Spectrum A, before EID; spectrum $B$, during EID. $p<1 \times 10^{-10}$. 


$$
\dot{\theta}(t)=-\frac{j}{e} \frac{\eta}{\sigma_{m}} \theta(t),
$$

where $j$ is the current density $\left(\mathrm{A} / \mathrm{cm}^{2}\right), e$ is the electronic charge $\left(1.6 \times 10^{-19} \mathrm{C}\right), \sigma_{m}$ is the number of sites per unit area $\left(6.2 \times 10^{14} \mathrm{~cm}^{-2}\right), \eta$ is the desorption efficiency, and $\theta$ is the coverage (relative). Also,

$$
\dot{\theta}(t)=\left(-3.24 \times 10^{19} S / A \sigma_{m}\right) \Delta p(t),
$$

where $S$ is the system pumping speed (liter/sec), $A$ is the surface area $\left(\mathrm{cm}^{2}\right)$, and $\Delta p(t)$ is the change in system pressure during electron bombardment (Torr).

Since the initial coverage was unknown in this experiment, only the product $\theta \eta$ may be determined, given by

$$
\theta(t) \eta=\frac{3.24 \times 10^{19} S \Delta p(t)}{A j / e}
$$

For $\mathrm{CO}$ desorbing from stainless, it was found that $\theta \eta=2.6 \times 10^{-5}$ molecules/electron for an electron energy of $555 \mathrm{eV}$ and a current density of $0.044 \mathrm{~mA} / \mathrm{cm}^{2}$. This value is applicable to the stainless in its cleanest state (after $40 \mathrm{~h}$ of EID). The total amount of $\mathrm{CO}$ desurbed was of the order of $10^{17}$ molecules, which corresponds to a monolayer on the sample surface $\left(135 \mathrm{~cm}^{2}\right)$. At least twice as much hydrogen was desorbed, but most of this probably came from the bulk.

After electron bombardment, $\mathrm{N}_{2}$ coverage as a function of pressure was measured for two isotherm temperatures. The surface was then saturated with oxygen $\left(10^{-7}\right.$ Torr for $\left.3 \mathrm{~h}\right)$, and the isotherms were remeasured. These data are presented in Fig. 9, corrected for background pressure. The most obvious features of these isotherms are the large values of $\sigma$ and the small variation in $\sigma$ with pressure. The isotherm flatness may be interpreted as an indication of the surface heterogeneity induced by the chemical cleaning and/or by the EID. The desorption of $\mathrm{CO}$ and $\mathrm{H}_{2}$ probably has uncovered many high-energy sites on the surface-for example, at grain boundaries, dislocations, and vacancies in the surface oxide. If such heterogeneous sites existed, an adsorbed nitrogen molecule would be slow in finding an equilibrium site because of reduced surface mobility. The very long equilibrium times observed, as compared to those for $\mathrm{N}_{2}$ on Pyrex, support this argument. The large number of molecules adsorbed at a pressure of $1 \times 10^{-9}$ Torr $\left(\sigma=6 \times 10^{13}\right.$ molecules $\left./ \mathrm{cm}^{2}\right)$ is also evidence of a higher surface binding energy. Table I shows a comparison of physisorbed nitrogen on several

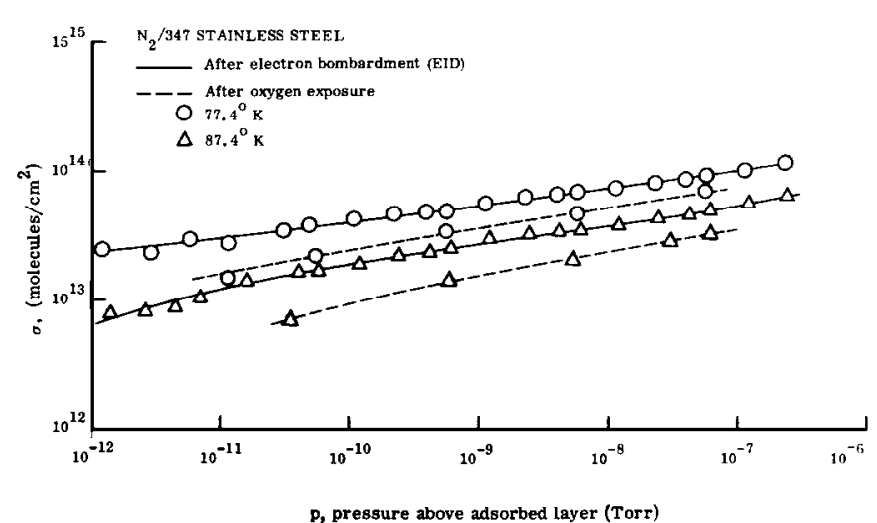

F1G. 9. Physical adsorption isotherms of nitrogen on 347 stainless steel for two surface conditions.

adsorbents at a pressure of $10^{-9}$ Torr, from which it is obvious that the coverage (based on geometrical area) is unusually high at low pressures. Troy and Wightman's data ${ }^{4}$ on uncleaned 304 stainless and Ricca and Medana's data ${ }^{3}$ on Pyrex were extrapolated from their D-R plots to this pressure. Their surfaces are evidently far less heterogeneous than the stainless in this work.

To investigate the possibility that EID had exposed (by desorption) a large number of energetic adsorption sites, the surface was exposed to oxygen at a pressure of $1 \times 10^{-7}$ Torr for several hours. The permanent work function change observed during the oxygen exposure exceeded $1 \mathrm{eV}$. One possible interpretation of the large work function change during reexposure to oxygen is that much of the surface oxide had been removed by EID. The isotherms obtained after the oxygen treatment show a substantial change in surface condition; the isotherm slopes are greater and the value of $\sigma$ was significantly lowered. Oxygen presumably reacted with the metal surface atoms to reduce the number of energetic sites available for the $\mathrm{N}_{2}$ molecules.

These data were fitted to the D-R equation as shown in Fig. 10, where the least-squares analyses of the data are represented by the solid and dashed lines. The magnitude of the mean energy of adsorption, $\mathrm{B}^{-\frac{1}{3}}$, is quite different for the two surface conditions- $-3.13 \mathrm{kcal} / \mathrm{mole}$ for the EID-cleaned surface as compared to 2.78 $\mathrm{kcal} /$ mole for the oxygen-treated surface. The isosteric heats for the two conditions give further evidence of the effect of oxygen treatment on the surface. Figure 11 is a plot of $q_{\mathrm{st}}$ vs $\sigma$. Since $\sigma$ varied only slightly with pressure, the heats could only be obtained for a limited range

\begin{tabular}{|c|c|c|c|c|c|}
\hline Adsorbent & $\stackrel{T_{a}}{(\mathbf{K})}$ & Technique & $\stackrel{\sigma}{\text { (molecules } / \mathrm{cm}^{2} \text { ) }}$ & $\begin{array}{c}\text { Surface } \\
\text { treatment }\end{array}$ & Author \\
\hline $\begin{array}{l}347 \text { SS } \\
347 \text { SS } \\
\text { Pyrex } \\
\text { Pyrex } \\
\text { Pyrex } \\
304 \text { SS }\end{array}$ & $\begin{array}{l}77.4 \\
77.4 \\
77.4 \\
77.4 \\
77.3 \\
77.0\end{array}$ & $\begin{array}{l}\text { Dynamic } \\
\text { Dynamic } \\
\text { Dynamic } \\
\text { Static } \\
\text { Dynamic } \\
\text { Static }\end{array}$ & $\begin{array}{l}5.5 \times 10^{13} \\
3.6 \times 10^{13} \\
4.5 \times 10^{12} \\
1.2 \times 10^{12} \\
7 \times 10^{11} \\
3.2 \times 10^{12}\end{array}$ & $\begin{array}{l}a, b, c, d \\
a, b, c, d, c \\
b, c \\
c \\
c \\
c\end{array}$ & $\begin{array}{l}\text { This work } \\
\text { This work } \\
\text { This work } \\
\text { Hobson and Armstrong (Ref. 2) } \\
\text { Ricca and Medana (Ref. 3) } \\
\text { Troy and Wightman (Ref. 4) }\end{array}$ \\
\hline
\end{tabular}
of coverage. A value of $7.0 \mathrm{kcal} /$ mole for the EID-

TABLE I. A comparison of $\sigma$ at $1 \times 10^{\rightarrow}$ Torr for $\mathrm{N}_{2}$ on several adsorbents.

\footnotetext{
- Vacuum fired. b Chemically cleaned. c Baked out. a EID. a Exposed to oxygen.
} 


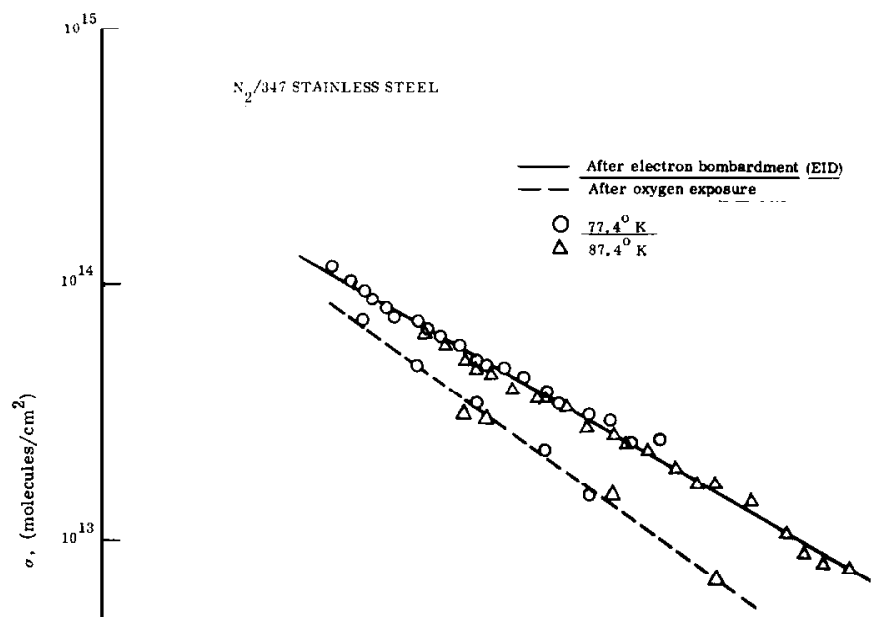
FIG. 10. Dubinin-Radushkevich
less steel for two surface conditions.

cleaned condition can be compared to a value of 6.2 $\mathrm{kcal} / \mathrm{mole}$ for the oxygen-treated condition at a coverage of $3.5 \times 10^{13}$ molecules $/ \mathrm{cm}^{2}$. This decrease in binding energy of the nitrogen on the oxygen-treated stainless demonstrates the reduction in the number of energetic sites available. It is apparent, however, that the oxygentreated surface is still quite heterogeneous if compared to the 304 stainless surface studicd by Troy and Wightman. ${ }^{4}$ They obtained a value for the isosteric heat of $4.4 \mathrm{kcal} /$ mole that varied only slightly over the range of

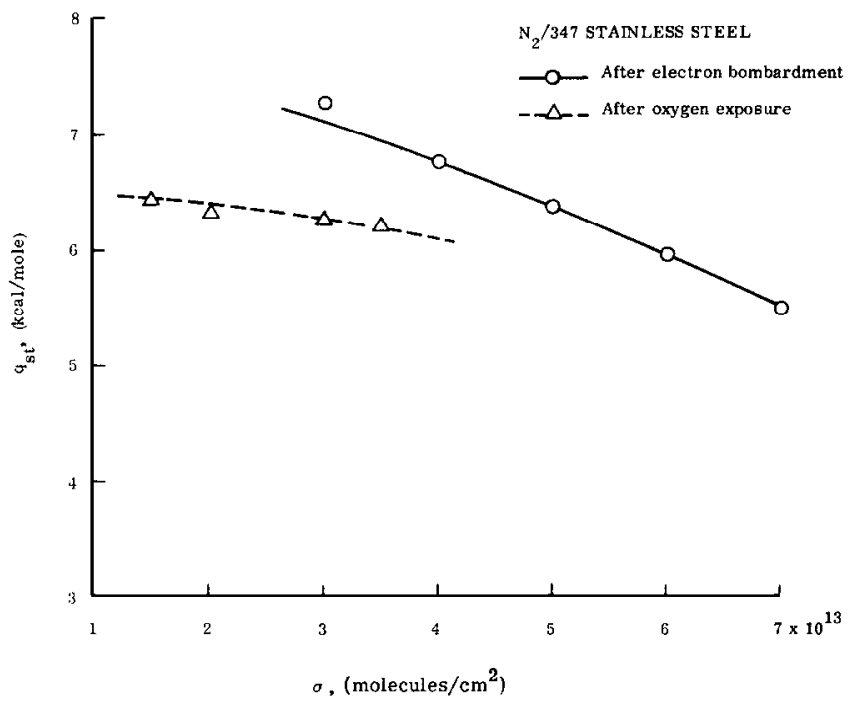

FIG. 11. Isosteric heats of adsorption, $q_{\mathrm{st}}$, as a function of $\sigma$ for nitrogen on 347 stainless steel for two surface conditions. coverage studied $(0.025 \leq \theta \leq 0.08)$. Since 347 and 304 are very similar in composition and since both surfaces are covered with oxide, it is possible that the greater heterogeneity of the 347 surface is the result of relatively cleaner surface conditions obtained in this work and/or from the chemical cleaning pretreatment.

\section{$\mathbf{N}_{2} /$ Polycrystalline Nickel}

After bakeout, the surface of the nickel adsorption vessel was cleaned by EID by using a current density of $0.11 \mathrm{~mA} / \mathrm{cm}^{2}$ and electron energies between 100 and $555 \mathrm{eV}$. The predominant gases observed during bombardment were $\mathrm{H}_{2}$ and $\mathrm{CO}$. The change in surface coverage during bombardment may be calculated for each species by Eq. (6), which gives

$$
(\Delta \theta)_{i}=\left(-3.24 \times 10^{19} S_{i} / A \sigma_{m}\right) \int_{0}^{\delta t} \Delta p_{i}(t) d t .
$$

The amount of $\mathrm{CO}$ and $\mathrm{H}_{2}$ desorbed, as calculated from Eq. (8), corresponds to $(\Delta \theta)_{\mathrm{CO}}=0.38$ and $(\Delta \theta)_{\mathrm{H}}=1.85$. Since hydrogen is present in the bulk of the nickel and also permeates through from the outside of the adsorption vessel, it is difficult to assess the significance of the change in hydrogen coverage. The value of $\Delta \theta$ obtained for $\mathrm{CO}$, however, seems to be reasonable.

A measure of the product $\theta \eta$ for $\mathrm{CO}$ on nickel was made after the work function indicated little change with additional bombardment (low surface coverage). A value of $4.1 \times 10^{8}$ (molecules $/ \mathrm{cm}^{2}$ ) sec ${ }^{-1}$ was obtained for an electron energy of $555 \mathrm{eV}$ and a current density of $0.11 \mathrm{~mA} / \mathrm{cm}^{2}$. This gas desorption flux corresponds to a value of $[\theta \eta]_{\mathrm{Co}^{555}}=6 \times 10^{-7}$ molecules/electron.

Figure 12 shows the variation in work function, $\Delta \varphi$ vs $j t / e$. Only a small change in work function was observed after a bombardment does of $j t / e=6 \times 10^{19}$ electrons/ $\mathrm{cm}^{2}$. The shape of the curve is similar to that obtained for stainless steel, but the maximum change is less than $0.2 \mathrm{eV}$, as compared to a change of about $1.1 \mathrm{eV} \mathrm{ob-}$ tained on the stainless steel. One possible interpretation of the small change in work function is that the surface was relatively clean at the beginning of EID as a result

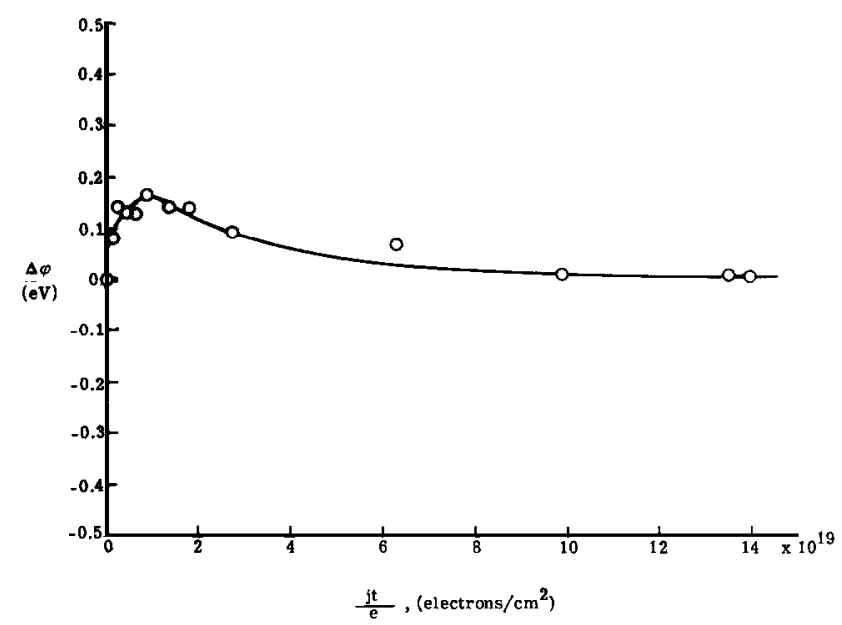

F1G. 12. Work function variation, $\Delta \varphi$, as a function of electron bombardment dose on nickel. 


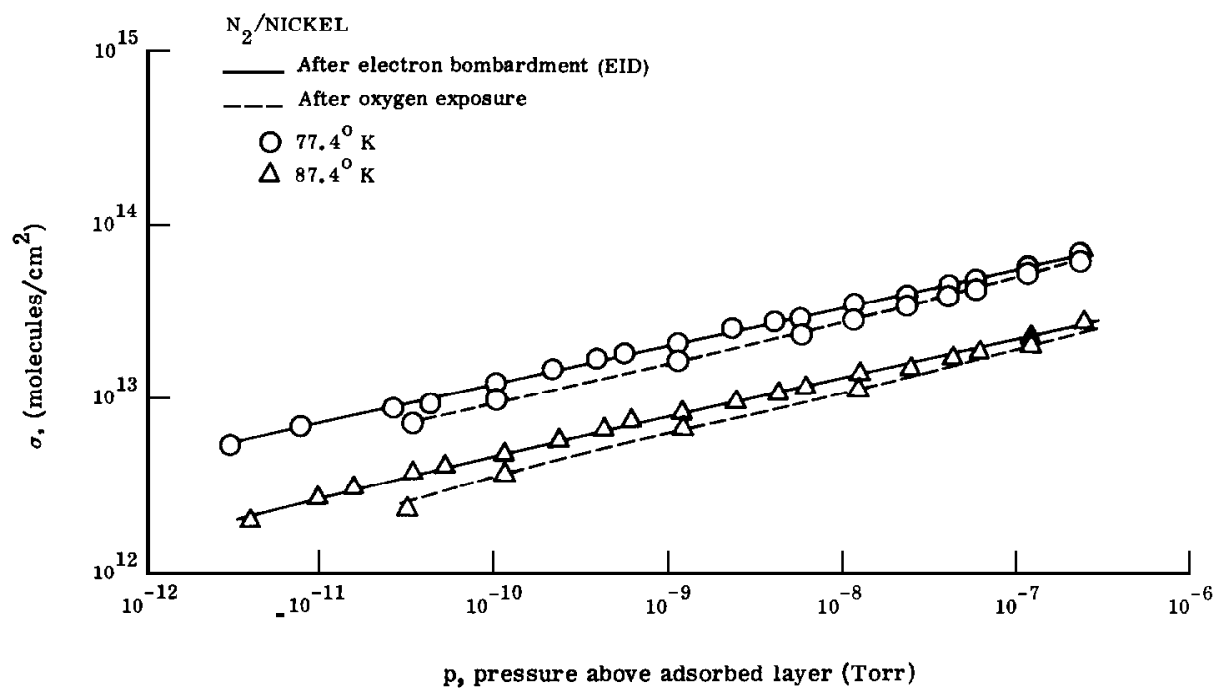

FIG. 13. Physical adsorption isotherms of nitrogen on nickel for two surface conditions.

of the surface oxygen being incorporated into the bulk during bakeout at $4500^{\circ} \mathrm{C} .15$ When the nickel surface was reexposed to oxygen, a substantial $\Delta \varphi$ was observed $(>+1 \mathrm{eV})$, but after pumping for about $3 \mathrm{~h}$ (oxygen supply off) the work function change had decreased to about $0.3 \mathrm{eV}$, which implied that a substantial fraction of the adsorbed oxygen had disappeared from the surface (desorbed or incorporated into the bulk at room temperature). Furthermore, when the surface was electron bombarded for a short time $\left(5 \mathrm{~min}\right.$ at $\left.1 \mu \mathrm{A} / \mathrm{cm}^{2}\right)$ the work function change decreased to less than $0.1 \mathrm{eV}$.

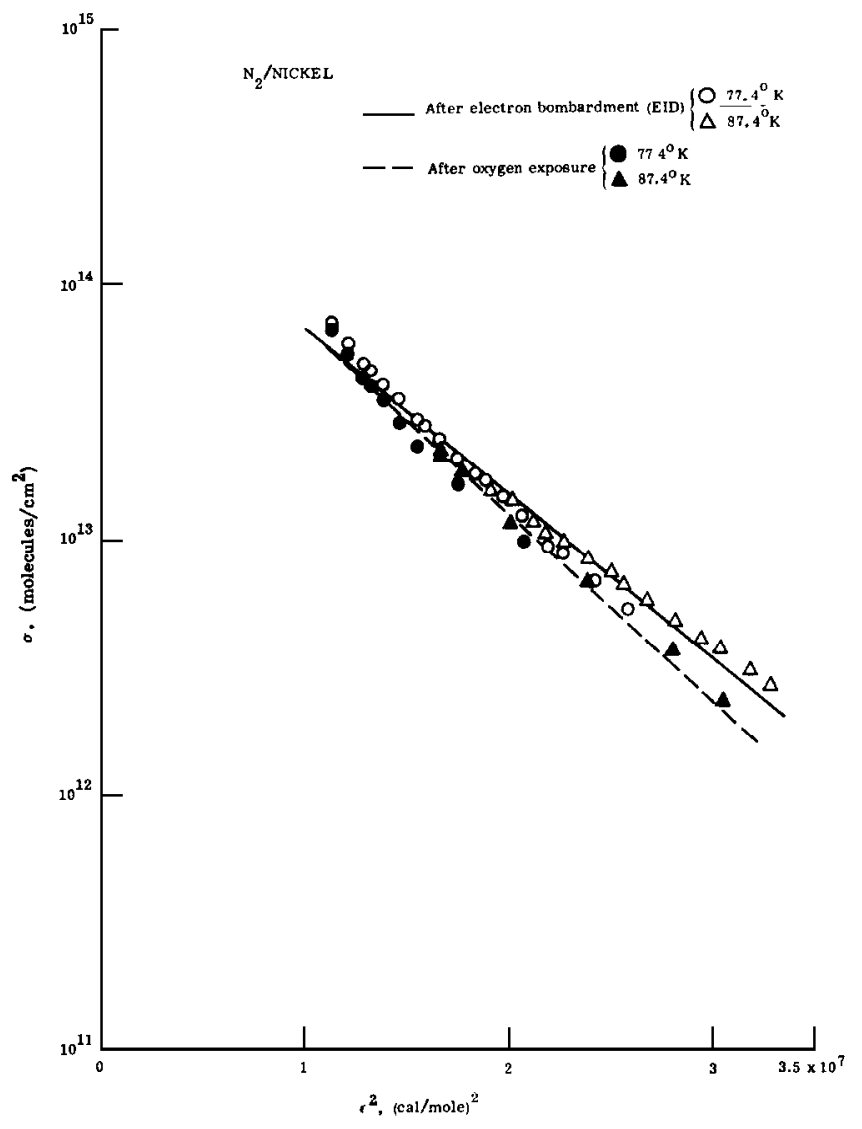

FIG. 14. Dubin-Radushkevich plots of nitrogen on nickel for two surface conditions.
Immediately after EID cleaning, the isotherm data for nitrogen on nickel were obtained. The sample was then exposed to oxygen $\left(9 \times 10^{-4}\right.$ Torr sec), after which the oxygen was pumped away and the surface was given a very mild electron bombardment $\left(2 \times 10^{15}\right.$ electrons $/ \mathrm{cm}^{2}$ ). The isotherm data for nitrogen on oxygen-treated nickel were then obtained. Figure 13 shows the adsorption isotherms of nitrogen on nickel before and after exposure to oxygen. It is immediately apparent that the isotherms are steeper than those observed for the stainless, which indicates a more homogeneous surface. The nitrogen isotherms obtained after the nickel was exposed to oxygen show only a small change compared to the isotherms taken after EID.

The fit of the data to the D-R equation is shown in Fig. 14, and the D-R parameters are presented in Table II. A large temperature effect is indicated for the two isotherms taken after EID. The correlation coefficients for each temperature are quite good, 0.998 , but for the combined data the coefficient drops to 0.991 . This clearly indicates some dependence on temperature ${ }^{16-17}$; however, the number of points taken for the isotherms following oxygen exposure prevents drawing a firm conclusion about a temperature effect. The calculated monolayer coverage given in Table II implies that the oxygen treatment increased the effective surface area of the nickel sample. This may be the result of surface disordering or reordering produced by chemisorption and/or incorporation. Surface reordering during oxygen chemisorption has been observed. ${ }^{18}$ It is probable that a fraction of the oxygen on the nickel surface in this work was chemisorbed since it only disappeared after electron bombardment. Incorporation could have been promoted by the electron bombardment since no significant gas desorption was observed during the bombardment. ${ }^{19}$ (No atomic or molecular oxygen appeared in the mass spectra, and there was also no increase in the $\mathrm{CO}$ or $\mathrm{CO}_{2}$ peak heights.) Furthermore, incorporation (following chemisorption) probably occurs by a place- 
TABLE II. D-R constants for the system $\mathrm{N}_{2} / \mathrm{Ni}$.

\begin{tabular}{|c|c|c|c|c|c|}
\hline $\begin{array}{l}\text { Surface } \\
\text { treatment }\end{array}$ & $\left(\begin{array}{c}T_{a} \\
\left({ }^{\circ} \mathrm{K}\right)\end{array}\right.$ & $\begin{array}{l}\text { Number } \\
\text { of data } \\
\text { points }\end{array}$ & $\begin{array}{c}B^{-!} \\
\text {(kcal/mole) }\end{array}$ & $\frac{\sigma_{m}}{\left(\text { molecules } / \mathrm{cm}^{2} \text { ) }\right.}$ & $\begin{array}{c}\text { Correlation } \\
\text { coefficient }\end{array}$ \\
\hline After EID & $\begin{array}{c}77.4 \\
87.4 \\
77.4 \text { and } 87.4\end{array}$ & $\begin{array}{l}18 \\
18 \\
36\end{array}$ & $\begin{array}{l}2.39 \times 10^{3} \\
2.76 \times 10^{3} \\
2.60 \times 10^{3}\end{array}$ & $\begin{array}{l}4.67 \times 10^{14} \\
1.96 \times 10^{14} \\
2.90 \times 10^{14}\end{array}$ & $\begin{array}{l}0.998 \\
0.998 \\
0.991\end{array}$ \\
\hline After $\mathrm{O}_{2}$ & $\begin{array}{c}77.4 \\
87.4 \\
77.4 \text { and } 87.4\end{array}$ & $\begin{array}{r}9 \\
5 \\
14\end{array}$ & $\begin{array}{l}2.22 \times 10^{3} \\
2.54 \times 10^{3} \\
2.45 \times 10^{3}\end{array}$ & $\begin{array}{l}5.93 \times 10^{14} \\
2.75 \times 10^{14} \\
3.56 \times 10^{14}\end{array}$ & $\begin{array}{l}0.993 \\
0.999 \\
0.994\end{array}$ \\
\hline
\end{tabular}

exchange mechanism, which suggests a displacement of metal atoms from their lattice position toward the surface as oxygen diffuses into the bulk. The disordered accumulation of these atoms at the surface would increase the surface area.

The plots of isosteric heats of adsorption vs coverage for nitrogen on nickel are presented in Fig. 15. Very little change is observed with coverage for either surface condition. The mean values are about $5.7 \mathrm{kcal} / \mathrm{mole}$ for the surface following EID and about $5.3 \mathrm{kcal} / \mathrm{mole}$ for the surface following oxygen exposure (consistent with the calculated $\mathrm{D}-\mathrm{R}$ parameters given in Table $\mathrm{II}$ ). The $5.7 \mathrm{kcal} /$ mole heat of adsorption at a coverage of approximately $5 \times 10^{12}$ molecules $/ \mathrm{cm}^{2}$ may be indirectly compared to the data of Baker and Fox ${ }^{20}$ for krypton on nickel films by using the ratio $q_{\mathrm{st}}\left(\mathrm{N}_{2}\right) / q_{\mathrm{st}}(\mathrm{Kr})-1.15$, obtained from the work of Troy and Wightman. ${ }^{4}$ Baker and Fox found the heat of adsorption at a coverage of

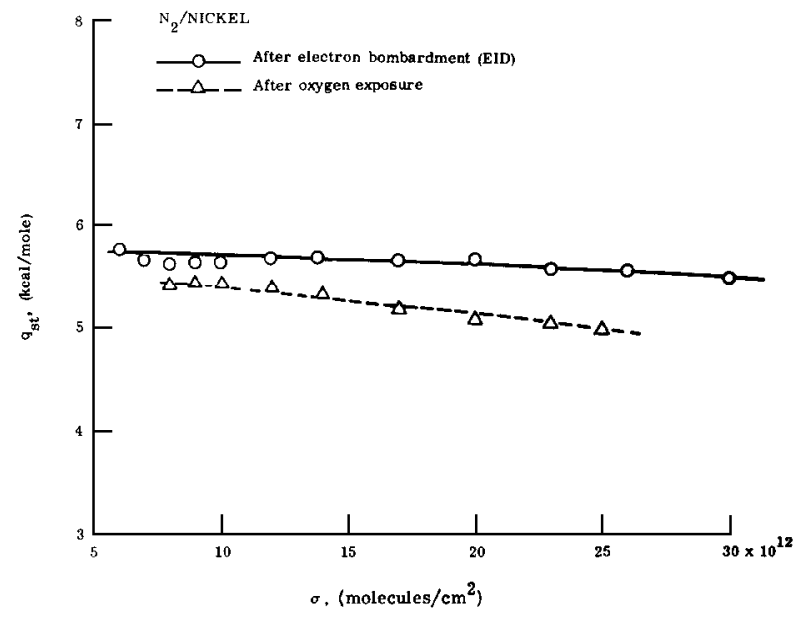

Fig. 15. Isosteric heat sof adsorption, $q_{s t}$, as a function of $\sigma$ for nitrogen on nickel for two surface conditions.
$5 \times 10^{12}$ molecules $/ \mathrm{cm}^{12}$ to be $5.0 \mathrm{kcal} / \mathrm{mole}$, which implies that they would find for nitrogen on nickel a heat of about $5.75 \mathrm{kcal} /$ mole.

During the time nitrogen was present in the system, the EID/work function cathode was not heated, in order to eliminate the possibility of exciting nitrogen molecules by the hot filament. This procedure was used to prevent nitrogen in an excited state from chemisorbing on the nickel. When the nitrogen had been evacuated, work function measurements were made to see if ground-state nitrogen had chemisorbed on the nickel. No change in work function was observed.

1D. M. Young and A. D. Crowell, Physical Adsorption of Gases (Butterworth, London, 1962).

${ }^{2} J$. P. Hobson and R. A. Armstrong, J. Phys. Chem. 67, 2000 (1963).

${ }^{3} \mathrm{~F}$. Ricca and R. Medana, Ric. Sci. 4, 617 (1964).

${ }^{4} \mathrm{M}$. Troy and J. P. Wightman, J. Vac. Sci. Technol. 7, 429 (1970).

5Y. Tuzi and T. Saito, J. Vac. Sci. Technol. 6, 238 (1969).

${ }^{6} \mathrm{~L}$. H. Germer, E. J. Scheibner, and C. D. Hartman, Philos. Mag. 5, 222 (1960)

${ }^{7} \mathrm{P}$. M. Gundry, J. Haber, and F. C. Tompkins, J. Catal. 1, 363 (1964).

${ }^{8}$ L. H. Germer and A. U. MacRae, J. Chem. Phys. 36, 1555 (1962).

${ }^{9}$ H. F. Winters, D. E. Horne, and E. E. Donaldson, J. Chem. Phys. 41, 2766 (1964).

${ }^{10}$ F. Steinrisser and E. N. Sickafus, Phys, Rev. Lett. 27, 992 (1971).

"1R. A. Outlaw and R. E. Stell, J. Vac. Sci. Technol. 8, 608 (1971).

${ }^{12} \mathrm{~J}$. D. Buckingham and P. N. Thorne, "Third Cz. Conference on Electronics and Vacuum Physics Transactions," 1965, p. 375.

${ }^{13} \mathrm{~N}$. Hansen, Vak.-Tech. 11, 70 (1972).

${ }^{14}$ J. P. Hobson and R. A. Armstrong, J. Phys. Chem. 67, 2002 (1963).

${ }^{15}$ A. Klopfer, private communication.

16A. Schram, Nuovo Cimento Suppl. 5, 309 (1967); 5, 291 (1967)

${ }^{17} \mathrm{~J}$. Shien-Chung Jen and J. Pinckney Wightman, J. Vac. Sci. Technol. 9, 1470 (1972).

${ }^{18}$ L. H. Germer and A. U. MacRae J. Appl. Phys. 33, 2923 (1962).

"A. Klopfer, J. Vac. Sci. Technol. 9, 301 (1972).

20B. G. Baker and D. G. Fox, Trans. Faraday Soc. 61, 2001 (1965). 